\title{
Response to "Utilitarianism Shot Down by Its Own Men" by Tuija Takala (CQ Vol 12, No 4)
}

\section{Takala Shoots Herself in the Foot}

\section{John Harris}

In a lively, interesting, and provocative paper Tuija Takala charges Julian Savulescu and me with bringing utilitarianism into disrepute and indeed with attempting to shoot it down, presumably in flames. ${ }^{1}$ Takala does not mince words. When she suggests that in our writings "utilitarianism is turning into the monster its critics always thought it was" (p. 447), she is associating herself with those who charge us (and others) with propounding, again her words, the "inhumane theory that allows the sacrifice of minorities, the killing of the innocent, and simplistic calculations on the value of life" (p. 447). Perhaps surprisingly for someone who identifies herself strongly with utilitarianism, Takala seems to take the worst and most ignorant critics of consequentialism generally, and of utilitarianism in particular, at face value and suggests that because their lazy, tendentious, and misdirected attacks on those they take to be utilitarians are often made against Savulescu and me that we somehow bear responsibility for this and for any charges they make, however ill judged or poorly supported by evidence.

Given that Takala admits, "Personally I would go along with many nor- mative suggestions presented by Harris and Savulescu" (p. 453), it is not clear what precisely her complaint is. If she shares those normative conclusions, which she has suggested others condemn as inhumane, then she is also guilty as charged; if she does not, she still owes us an account of how and to what extent the charges are well founded. In short, she must put up or shut up. If she can make good her suggestion that we are actually guilty of monstrous or inhumane proposals, then she must show how what we say is monstrous and inhumane. It is not enough simply to imply that some people think so and that, even though she does not herself share their views, this somehow gives Savulescu or me a reason for soul searching, remorse, or retraction. I show in this response that Takala has singularly failed to put up; she has failed to sustain any of the claims against me that would justify any of her charges, however obliquely targeted, and so any damage done to utilitarianism must be the result of friendly but misdirected fire by its own woman-Takala herself!

Julian Savulescu is well able to defend himself, so I concentrate here on the charges leveled against my own work. Takala seems to have two main complaints against me. The first is that I give importance to rationality; and, more particularly, that I appeal to the 
rationality of actions as one touchstone of their acceptability (or to the irrationality of actions as a reason for rejecting them). To this I plead guilty and note only that purported reasons against the use of rationality that do not appeal to or use rational argument are in danger of being less than convincing. It is also not a little odd to hear a philosopher complaining about appeals to rationality in those with whom they disagree. It is difficult to understand Takala's complaints against my deployment of appeals to rationality. I will examine them in a moment when I look at her treatment of the survival lottery (SL).

The second complaint is that I oppose freedom of choice and seek to impose my views on others. This is altogether more serious, but surprisingly Takala can find (or at least cites) only two examples of my antilibertarian agenda, neither of which to the remotest degree demonstrates the totalitarian tendencies of which she complains.

\section{The Survival Lottery}

I begin, however, with her discussion of an early paper of mine, written in 1973 and first published in 1975, which, I admit, has on occasion been used as a stick with which to beat utilitarianism.

This is how Takala introduces the survival lottery:

Harris's article "Survival Lottery" also seems to have contributed to the reputation of utilitarianism as an appalling moral theory. To sum up the contents of this influential article, Harris starts from the empirical observation that the number of donated vital organs is too small to meet the demand for transplants, and he suggests that a "survival lottery" could solve the problem. The (voluntary) lottery would be arranged so that, whenever sacrificing one person as an organ donor could save two or more lives, a participant in the lottery would be pressed into service as the donor on having her ticket drawn by proper authorities. She is killed and her organs distributed to those in need. It would be rational for everyone to take part in the lotterysimple calculations show that, statistically speaking, everyone has a better chance of living a long and healthy life in a society where the lottery is operated than in a society where it is not.

A choice between accepting or rejecting Harris's lottery is not a choice between accepting or rejecting utilitarianism, as some critics have thought. It is a choice between different notions of rationality, or the role of rationality, in bioethics. Not everybody sees a longer life span (in the terms defined by the organ lottery) as a rational choice. The early Harris stated quite clearly that the scheme must be voluntary and hence left room for different views of what is rational. If people in a given society hold the lottery to be a rational model, they can establish the system and benefit everyone (in the way that they see themselves benefited), but if they do not, the lottery should not be run. For the former group there would be good utilitarian reasons to operate the lottery, and for the latter there would be equally good utilitarian reasons not to. (p. 449)

It is important to clarify Takala's interpretation of the SL. The SL was predicated on the idea that people love life and fear death, hence that premature death is unwelcome. It imagines the perfection of organ transplantation as a therapy to a greater extent than has ever yet been achieved. It supposes that transplants are a reliable and minimally risky procedure that restores health and life expectancy to that which is normal for the general health profile of the individual requiring transplants. The SL would only be used where a number of people faced a premature and unwelcome death and where organs from a third 
party would be the only way their lives could be saved. Although the SL would add a new risk of premature death to any society that adopted it (the risk of being chosen to be an organ donor), many existing threats to life would be removed. Thus if people wanted to reduce their risk of premature death, the SL would be rational choice and there would be no prudential reasons against introducing it. So, the SL would be rational and prudential for any lifeloving, death-fearing, risk-averse person. It would be "voluntary" 2 in the sense that it would be adopted only by the will of the people expressed democratically.

Note that there is no question of myself nor any other wicked consequentialist imposing the lottery on others because I or we think it best. The SL is an open invitation to anyone to consider whether, given their values, fears, and desires, the SL would not be both prudential and ethical.

Thus when Takala says, "The early Harris stated quite clearly that the scheme must be voluntary and hence left room for different views of what is rational" (p. 449), this is not quite right. It is not that there is room for different views of what is rational because the scheme is voluntary. Rather, the scheme is consensual and will only appeal to people who find it both rational and ethical. It is not that I imagine different conceptions of rationality, which are somehow accommodated only in a climate of liberty, still less that I outline a particular conception of rationality and try to impose it on others. Rather, it is the case that rationality presupposes people suiting means to ends; and unless saving life, or reducing the risk of premature death, is an end they themselves have adopted, the SL will not appeal and hence will not figure as a possible means in the rational plans of any moral agents.
So, when Takala says, for example, that the SL involves "a choice between different notions of rationality, or the role of rationality, in bioethics" (p. 449), this is not true. It is not that I deploy a conception of rationality and insist that it is the only one. I appeal to the notion of rationality of the agents themselves. I say, "If you want to have a better chance of long term survival, you will choose the SL." So far from appealing to some personal or esoteric conception of rationality, I appeal to what the agent himself or herself would regard as rational, given what they want or value.

I think Takala concedes that the SL is not a proposal that could bring consequentialism into disrepute because it must be freely chosen by any society that implements it. Whether the SL is one of the normative conclusions she shares with me she does not say. However, having, perhaps surprisingly, identified the SL as a reputable contribution to ethical discussion, Takala's complaints begin.

\section{Freedom of Choice}

Takala complains that Savulescu and I have not only rejected freedom of choice but that in doing so we have become a species of ethical imperialist. She suggests:

In the recent writings of John Harris and Julian Savulescu, however, the freedom of choice seems to be absent. Morality is not, so it seems, any more about the subjective pains and pleasures, or preferences, of the individuals concerned, but about their best possible lives, as judged by Harris and Savulescu. (pp. 449-450)

This passage is, I am sorry to have to say, a travesty! Normative ethics is always about coming to conclusions about right and wrong, and those conclusions are, of course, based on the 
combination of evidence and argument adduced by the person drawing the conclusions. Such conclusions are always offered, by me at any rate, first for consideration and, certainly, for possible rejection. If, however, they are convincing, or at least if no good and sufficient arguments can be adduced against them, then they should be accepted by any rational person. Whether they should be imposed on others is always a further and separate question. Although I do not rule out the possibility of recommending the imposition of moral conclusions on unwilling others, this, in a democratic consensual society, should always be a last resort and should only be recommended with reluctance in extremely important cases. The fact that most societies have, and most people support, laws against murder, for example, shows that most people accept the necessity for the imposition of morality in some cases. The point is that I do not recommend, nor do I believe I have ever recommended, compulsion or the "imposition" of moral conclusions in either of the two sets of circumstances identified by Takala. Her first "incriminating" example is in the context of communicating "facts" or "judgments" to others rather than that of imposing constraints on action. However, Takala says that I give the distinct impression of imposing my beliefs on others simply because I judge those beliefs to be right:

This is at least my impression when Harris writes:

I may ... tell you that you have particular genetic mutations, or indeed have a terminal illness, if I judge that it is important for you to know. ... (p. 427) ${ }^{[3]}$

In the cited article Harris argues that people should be told about their genetic makeup even if they do not want to know. According to him, the fact that (he thinks that) it would be rational for a person to know about her genetic constitution forms a sufficient moral reason for informing her even against her express wishes. This applies to everyone and to all cases, even when no cure is available. To know things about one's genetic makeup that will have a bearing on one's life is rational, because it allows persons to make their life plans realistically in the light of available relevant information. (p. 450)

Again, and again with both reluctance and regret, I have to record that what is attributed to me here bears little relation to what I have actually said, still less believe. It is not the case that "according to him, the fact that (he thinks that) it would be rational for a person to know about her genetic constitution" that "forms a sufficient moral reason for informing her even against her express wishes." First, and obviously, I do not believe that the fact that I think something gives anyone a reason to accept it, let alone that it gives me a reason to impose it. If others have a reason to accept anything I say it is usually because it is right, either because it is rational or because the best combination of evidence and argument support it. The reason is never the fact that I believe it or say it! I have never claimed to be the arbiter (or even an arbiter) of what is rational.

Moreover, Takala has clearly misunderstood my views on the alleged existence of a right not to know. My views on this question have been set out in a number of places, and it would be tedious to rehearse them in detail. ${ }^{4}$ However, two clear things can be said. The first is that the reason there is no right not to know facts about oneselfor, as I would prefer to express it, "no right to remain in ignorance of facts about oneself" - has nothing to do with the alleged fact that the information giver has formed a judgment that "(he 
thinks that) it would be rational for a person to know about her genetic constitution." My thoughts about what is good for others play no part in my belief that they have no right not to be told what I think.

I do think that it is generally in a person's interests to have full information about themselves, but I have two quite independent and principled reasons for believing that there is no such thing as a right to remain in ignorance. First, because, like Takala, I believe strongly in freedom of choice, and given that knowledge is necessary for autonomous choice and, moreover, without relevant information the subject cannot make autonomous choices, knowledge is a necessary condition of freedom of choice. That is why it is always consistent with respect for autonomy to be given important knowledge about oneself, particularly medical and genetic knowledge. ${ }^{5}$ Thus, whereas "bare" liberty may support your right not to know, respect for your autonomy can never support such a right. The liberty not to be told is arguably weak when compared to the imperative to respect autonomy, with which I have argued it competes in cases of the giving of any information relevant to an agent's rational decisionmaking. I champion respect for freedom of choice, where choice is a "thick" concept implying autonomous choice rather than the simple expression of preference or bare liberty.

The second reason there is no right to remain in ignorance that could "trump" another's wish to tell the truth is that to grant such a right would create an incompatibility between competing rights of comparable force. Your right to remain in ignorance of facts that I know about you competes with my right to freedom of speech, to tell you things I believe important. ${ }^{6}$ If you really had a strong right not to know, then whenever you asserted that right against me you would be imposing your will on me, you would be curtailing my freedom of speech. Of course, that does not mean that I must tell you what I think, nor even that I ought to tell you when you do not want to know. It only means that you have no strong right that I refrain and that, if I do not refrain, I am not violating your rights (although I may be doing you wrong or even harm in some other way). To suggest that my telling you important facts about your life and your options amounts to my imposing my conception of the good life on you is a somewhat inflated claim. If anything, I am giving you what you objectively need for free choice, what you need to make judgments about what is good for your own life.

\section{Suggesting That People Have No Right to Avoid Their Responsibilities Is Not Tyrannizing over Them}

There is one further important difference between the case of telling others things they do not wish to hear and any other forms of imposing one's will on others. In the usual medical contexts in which the issue of telling patients the truth arises, ${ }^{7}$ the refusal of information by patients unreasonably imposes on their caregivers, and on health professionals, the responsibility for making decisions about the management of their condition and about many other things that are properly the patients' own.

For example, a wife, because her husband refuses information about the terminal nature of his condition, may have to make decisions about whether it would be better for him, or more consistent with what he would have wanted, to summon their children home from abroad and thereby risk giving unwelcome clues as to the seri- 
ousness of his condition, or to let him die without seeing them, again thereby protecting his ignorance. Or, a doctor may have to decide whether aggressive and burdensome therapy that might extend life a little is more or less appropriate than an earlier death with "nursing care only." These are not decisions that a patient can have a right to impose on others. ${ }^{8}$ If others voluntarily accept the imposition on them of such decisions, that is another matter; but then there are further dangers, the exploration of which is beyond the scope of this paper. Such dangers include the question of whether it is, all things considered, more dangerous to live in a society where medical paternalism is encouraged or discouraged or whether there is a risk of patients refusing information in the fog of mistaken beliefs about the nature of the information they have refused.

\section{Imposing Decisions on People with Disabilities}

The second (and only other) example of my totalitarian tendencies that Takala can find concerns people with disabilities. ${ }^{9}$

According to Harris, people with disabilities are just as valuable as those without ailments, but no rational being would choose to be disabled in the slightest and therefore, giving birth to disabled children should be avoided. ${ }^{10}$

I myself enjoy being healthy (whatever that means) and would prefer to stay healthy in the future, but I do not think that I can set objective standards for all others based on my experiences and expectations. As a person who is scared of treatments and pain, I would not like to be confronted with medical procedures, but I cannot argue that people who have to face them cannot rationally hold to have the "best life." We all value different things and dif- ferent lifestyles, and usually refrain from dictating each other's tastes. Why should "health" be a different type of value? (pp. 450-451)

Again I regret to have to say Takala is charging me with sins of which I am innocent. She insists on implying that I am somehow dictating to others. "We all value different things and different lifestyles, and usually refrain from dictating each other's tastes." 11 I always refrain from such a thing! I am in no way dictating to others. In the very paper from which Takala quotes, I explicitly make clear that to say that it is better not to produce disabilities where there is an alternative is not to say that people should be dictated to. I clearly state:

Most disabilities fall far short of the high standard of awfulness required to judge a life to be not worth living. This is why I have consistently distinguished having moral reasons for avoiding producing new disabled individuals from enforcement, regulation, or prevention of the birth of such individuals. This is why I have specifically and repeatedly said, (and feel I must say it again now) that for those who can only have children with disabilities, having such children may well be morally better, for the parents and for the children, than having no children at all. ${ }^{12}$

I do not see how Takala can persist in her claim that I attempt to dictate to others on these matters in the face of so specific and explicit a statement to the contrary, a statement of which she was well aware at the time of writing. Takala seems to think that articulating moral conclusions on the basis of clearly set out evidence and argument is tantamount to dictating what others should do. If that were so, all normative ethics would constitute assaults on freedom of choice and the SL would surely by now have become public 
policy in most civilized countries. Ethics is always "action guiding" in some sense, but "action dictating" and the foreclosing of options for others requires more, and more of a sort of theorizing that Takala has been quite unable to find in my writings, except possibly where she would herself agree.

I define disability as:

a condition that someone has a strong rational preference not to be in and one that is in some sense a harmed condition. For me then a harmed condition is defined relative both to one's rational preferences and to conditions which might be described as harmful, not relative to normal species functioning but relative to possible alternatives. ${ }^{13}$

There are the two essential elements to "disability," as I use the term: the first that it is rational to want to avoid or remove the disability, and the second that it must constitute a harm to the individual. If it is not a harm, it is not a disability. The test I proposed is as objective as it reasonably can be. A disability is any condition of which the following is true. That if a patient were to present unconscious in this condition (whatever it is) in the emergency department of a hospital and the condition were reversible but only if the staff act at once without the ability to consult the patient and if they fail to do so the condition will be permanent, then it is a disability if we would judge that they ought to reverse or remove it and would be negligent not to. Thus, even the loss of the last segment of a finger (a relatively trivial condition, to be sure) counts as a disability in this sense. I am not making a distinction between trivial and serious disabilities, nor am I to the slightest degree saying that life cannot be wonderful for people living with disabilities. I am simply suggesting that it is better not to be harmed, even to the slightest degree, and that the test I propose is as good as it is possible to get of what a "harm" is. I am also decidedly not saying that the test is always applicable in the sense that there is always an obvious answer. But I believe there usually is and that it is better to err on the safe side of avoiding harm, however slight that harm may be. ${ }^{14}$

On no basis whatsoever, then, Takala has suggested that Savulescu and I have claimed "superior knowledge of what is rational and therefore also morally right" (p. 452). I do not believe that either of us has ever made such a claim. Certainly, we have pointed out that certain conclusions are irrational or inconsistent with the likely goals, desires, or hopes of those who hold them. If we are persuasive in this, it is not because we claim or possess superior knowledge or better morality but because we are able to demonstrate the irrationality or inconsistency of the beliefs or conclusions we criticize. We have never attempted to "justify why [our] 'one truth' should matter to people who hold different moral ideas" (p. 453). Not only can both of us reasonably lay claim to more than just one idea (or "truth," as Takala prefers to call it), but also neither of us believe that our ideas should matter to others because we have superior knowledge or morality. We do, however, believe that our ideas should matter to any rational person if those ideas are supported by better evidence and argument or if we can show that the contrary beliefs of others are irrational or inconsistent. So, when Takala concludes, "The fact that their model is, in their view, 'rational' is not a sufficient reason" why the Savulescu or Harris view is right or better, she is certainly correct! Neither of us think that the fact that it is "in our view" rational or better provides any reason to accept it. We both believe, though, 
that the fact that an idea is irrational does constitute a reason for rejecting it, and the fact that it can be shown to be inconsistent with other beliefs or ideas that the agent holds does show that they cannot all be "right" or "rationally maintained." It does not, of course, show which of the inconsistent ideas or positions is wrong or should be abandoned.

\section{Methodology}

Finally, Takala says, "I do not know whether Harris and Savulescu count themselves as utilitarians. Harris has always been reluctant to reveal his methodology and normative background, although every now and then he admits to consequentialist tendencies" (p. 452). I have to say that I have never been reluctant to reveal my methodology; such as it is, it appears in plain view on every page I write and in every argument I have produced. It is true that I have not tried to give a name to, or a meta-account of, the methodologies that I use, but that is another thing. I am content for others to do that in the unlikely event that they have the time or interest for such an activity. ${ }^{15}$ As for the normative background, well, again, if I have such a thing, any competent reader has as much access to it as I do myself. It will surprise no one, however, if I admit that it is probably right to say that my approach is broadly consequentialist-with strong libertarian tendencies. I have never been a cardcarrying utilitarian, so perhaps it is not surprising that those who are find some reasons to criticize what I say.

\section{The New Heresy}

Takala is disarming in the extreme when she admits that our crime is really that we have committed heresy and, in doing so, have sinned against the one true faith:

My actual concern here is that, as long as Harris and Savulescu are perceived as utilitarians, their commitment to rationalism continues to contribute to the theory's already bad reputation, and the doctrine that I think should be given more room in bioethics is unfairly and unnecessarily dismissed from many ethical discussions. (p. 452)

She seems to think that we must not only bear the responsibility for the ill-judged perceptions of others but that it is right and proper that she should somehow contribute to these misjudgments and call us to account for some imagined heresy.

\section{Notes}

1. Takala T. Utilitarianism shot down by its own men. Cambridge Quarterly of Healthcare Ethics 2003;12(4):447-54. I should record that this feels like a family squabble, given that Tuija, Julian, and I are all friends, but as is well known, such disagreements can be both important and difficult.

2. Not my choice of term.

3. Harris J, Keywood K. Ignorance, information and autonomy. Theoretical Medicine and Bioethics 2001;22:415-36.

4. Takala cites a recent example, but they can be found also in: Harris J. The Value of Life. London: Routledge \& Kegan Paul; 1980.

5. See also: Harris J. Clones, Genes, and Immortality. New York: Oxford University Press; 1998.

6. I am assuming the information is given without malicious intent. Whereas even malicious "truth telling" may be defensible, such a thing raises additional issues not here relevant.

7. We are not talking here of my telling you unwelcome "home truths" like facts about how poor your philosophical arguments are, which you may not wish to know but hardly seem to raise important questions of human liberty versus totalitarianism.

8. Which is not to say that she must be told. Simply, it is the case that she has no entitlement to restrict the free, informed (and usu- 
ally compassionate) choice of others if, on balance, they believe it right to give the information.

9. I am, perhaps rashly, assuming that if Takala could have found other more plausible examples to substantiate her case she would have produced them. But, of course, "absence of evidence is not evidence of absence"!

10. Harris J. One principle and three fallacies of disability studies. Journal of Medical Ethics 2001;27:383-7. See also: Harris J. Is there a coherent social conception of disability? Journal of Medical Ethics 2000;26:95-100.

11. Emphasis added.

12. See note 10, Harris 2001. Emphasis is added to show that I specifically and explicitly exclude imposition of my views whether in the form of "enforcement, regulation, or prevention of the birth of such individuals." I do not see how I could be clearer on this point nor how Takala could justify her suggestion that this amounts to imposition of my views!

13. See note 10, Harris 2001.

14. For an extensive discussion of these issues, see note 6, Harris 1998;chap. 5.

15. One friend, as Tuija has noted, has tried to do this for me; see: Häyry M. What the fox would have said, had he been a hedgehog: on the methodological and normative approach of John Harris's "Wonderwoman and Superman." In: Playing God: Essays on Bioethics. Helsinki: Helsinki University Press; 2001:64-78. 